\title{
Frequency of Cervical Pre-Malignancy in Pregnant Women
}

\author{
Imrana Rasheed, ${ }^{1}$ Khadija Waheed, ${ }^{2}$ Sara Ejaz ${ }^{3}$, Javeria Mushtaq ${ }^{4}$
}

\begin{abstract}
The abnormal growth of precancerous cells on the surface of the cervix is cervical intraepithelial neoplasia (CIN). Cervical intraepithelial neoplasia is classified according to extent of the abnormal cell growth and is classified as low grade and high grade. Human papilloma virus, a sexually transmitted virus is commonly associated with CIN. A regular Pap smear test can detect CIN at early stages and this helps in treating disease at early stage and protection against human papilloma virus can be provided with vaccine.

Objective: To find the frequency of cervical premalignancy in pregnant women.

Patients and Methods: This cross - sectional study was conducted at Department of Obstetrics and Gynaecology, Lahore. A total of 260 patients were included in this study. Pap smear samples were collected and fixed in $95 \%$ alcohol solution. Smears were sent with a histopathology form for reporting.
\end{abstract}

\footnotetext{
${ }^{1}$ WMO, Dept of Obstetrics \& Gynaecology

Services Hospital, Lahore.

${ }^{2}$ Assistant Professor of Obstetrics \& Gynaecology

KEMU / Lady Aitchison Hospital, Lahore

${ }^{3}$ Associate Professor of Obstetrics \& Gynaecology

FJMU / Sir Ganga Ram Hospital, Lahore

${ }^{4}$ Department of Obstetrics \& Gynaecology

SIMS/Services Hospital, Lahore.
}

Date of Submission 22-02-2016

Date of Revision Received 14-07-2016

Date of Acceptance for Publication 02-08-2016

Conflict of Interest: None

Funding Source: None

\section{Contribution}

All the Authors have contributed in Study Design, Data Collection, Data Analysis, Data Interpretation, Manuscript Writing and Statistical Analysis.
Results: Mean age of the patients was $27.32 \pm 5.12$ years. Mean gestational age was $29.60 \pm 6.36$ weeks. Cervical pre-malignancy on pap smear was observed in 8 patients $(3.01 \%)$. All of them were CIN - I. Stratification with regard to history of smoking, history of oral contraception, low socioeconomic status, multiple marriages and early marriage was done.

Conclusion: Women having history of low socioeconomic status and oral contraceptive were more prevalent in developing CIN. It is recommended that cervical cancer screening by pap smear is for all women who are sexually active.

Key Words: Cervical intraepithelial neoplasia, Pap smear, HPV.

\section{Introduction}

The cervical pre-malignancy is also known as cervical intraepithelial neoplasia (CIN). CIN is defined as abnormal growth of squamous cells and premalignant transformation on the surface of the cervix. Abnormal cellular proliferation, abnormal epithelial maturation and cytological atypia are characteristics of CIN. CIN is mainly categorized into three types according to the extent of abnormal cell. i.e. CIN I, CIN II and CIN III. Early changes in the cervix which might become cancer can be detected with screening tool known as Pap smear. Pap smear can also detect early stages of cervical cancer which is usually asymptomatic. ${ }^{1}$

Following are the risk factors for cervical cancer: multiparity, smoking, age at first intercourse, socioeconomic status, oral contraceptive pills (OCP) usage, and human papillomavirus (HPV) infection. ${ }^{2}$ There are various types of HPV out of which 16 and 18 are consider being high risk and associated with CIN and cervical cancer, a sexually transmitted infection accounting for $60 \%$ of HPV positive invasive cervical cancers. Body's immune system takes almost $8-14$ months to clear most cases approximately $80 \%$ of HPV. $90 \%$ of 
the most common type of cervical cancer can be prevented with regular Pap smear every three yearly. ${ }^{3}$

In one study conducted in total 76 pregnant females Pap smear were taken and $21 \%$ showed CIN. ${ }^{4}$ In another study, conducted at Karachi, Pakistan, cervical smear was taken in 20,995 cervical smears taken in the obstetrics and gynaecological clinics showed $0.71 \%$ atypia. ${ }^{5}$ Another study conducted in India in which 300 pap smears were taken from patients who attended obstetrics and gynaecology showed cervical epithelial abnormalities in $5 \%$ of cases. ${ }^{6}$

Every three yearly Pap smear is recommended in women aged 18 to 69 years, who have ever been sexually active. Pregnant females should be counseled that properly collected Pap smear during pregnancy is not hazardous, only associated problems can be spotting or minor bleeding.

Chances of progression of CIN I to CIN III is $10-$ $16 \%$, CIN II to CIN III is $50 \%$ and $30 \%$ of women with CIN III would develop invasive cancer over 20 years period. ${ }^{1}$

In case of normal result pap smear should be repeated every three yearly, repeat smear after 6 months is recommended in case of inflammatory and borderline smear result, colposcopy is advised in case of CIN I, CIN II, CIN III, in case of suspected invasion or abnormal glandular cell advise urgent colposcopy biopsy. ${ }^{7}$

The rationale of conducting this study is to improve the detection rate of cervical intraepithelial neoplasia (CIN) in reproductive age group. It is evident from literature review mentioned above that study related to antenatal population used small number i.e. 76 cases of pregnant patients that showed $21 \%$ CIN in pap smear samples. ${ }^{4}$ Similarly, studies conducted in Pakistan and India screened both obstetrics and gynaecological patients showed up to 5\% of cervical epithetlial abnormalities. ${ }^{5,6}$ It means that study conducted in antenatal population showed high incidence of CIN as compared to both obstetrics and gynae patients. These studies indicated that pap smear is not taken regularly in reproductive age groups in Pakistan. In the proposed study, we took 260 pregnant women to collect the recent data of cervical pre-malignancy in reproductive age group. Cervical abnormalities usually occurs in reproductive age group, therefore when females are pregnant they mostly attend hospital and are concerned about their health and this is a time to offer them cervical screening. Moreover, screening for cancer of the cervix remains a neglected health care issue in Pakistan. Hence, every pregnant female who did not have
Pap smear in last three years should be offered pap smear during antenatal period.

\section{Patients and Methods}

It is a cross - sectional study conducted in Department of Obstetrics and Gynaecology, Lahore. Study was carried out over a period of six months.

Sample size estimated using 95\% confi-dence level with $5 \%$ margin of error with an expected percentage of cervical pre-malignancy i.e. $21 \%$ in pre-gnant women is $260 .^{4}$

Pregnant women who never have pap smear in last three years were included and following women were excluded. Pregnant women who have negative pap smear in last three years, patients with threatened miscarriage and patients with low lying placenta.

260 pregnant patients from antenatal clinic were selected after fulfilling the inclusion and exclusion criteria. After taking informed consent, each patient underwent clinical gynecological examination followed by cervical sampling. Patient was placed in lithotomy position and cervical sample was obtained by using a spatula. Pap smear samples were collected and fixed in $95 \%$ alcohol solution. Smears were sent with a histopathology form for reporting and were reported by consultant pathologist. CIN is the potentially premalignant transformation and abnormal growth of squamous cells on the surface of the cervix CIN is characterized by abnormal cellular proliferation, abnormal epithelial maturation and cytological atypia. Mainly, it is categorized into three types i.e. CIN I, CIN II, CIN III.

CIN I is Mild dysplasia, it is confirmed to the basal $1 / 3$ of epithelium.

CIN II is Moderate dysplasia, it is confirmed to this basal 2/3 of epithelium.

CIN III is Severe dysplasia may span more than $2 / 3$ of epithelium also known as carcinoma in situ. The study was submitted to hospital ethical committee for approval. Data was entered and analyzed using SPSS 17. Quantitative variables like age presented using mean and standard deviation. Qualitative variable like gender and cervical pre-malignancy (CIN I, CIN II, CIN III) was presented using frequency and percentages. Data was stratified for the variables like history of smoking, oral contraception, low socioeconomic status, multiple marriages and early marriage to address the effect of modifiers. Chi-square test was applied and $p$-value $\leq 0.05$ was considered as significant. 


\section{Results}

Regarding age distribution, 178 patients $(68.5 \%)$ were between $21-30$ years of age and 82 patients $(31.5 \%)$ were $31-40$ years old. Mean age of the patients was $27.32 \pm 5.12$ years. Mean gestational age was $29.60 \pm$ 6.36 weeks. Out of 260 patients, 21 (8.1\%) were mar-

Table 1: Descriptive Statistics of Age at Marriage, Pre Malignancy and CIN Grades.

\begin{tabular}{|l|l|r|c|}
\hline & $\begin{array}{c}\text { Age at } \\
\text { Marriage }\end{array}$ & Number & Percentage \\
\hline \multirow{3}{*}{$\begin{array}{l}\text { Age at } \\
\text { Marriage }\end{array}$} & $<19$ & 21 & 08.1 \\
\cline { 2 - 4 } & $20-24$ & 164 & 63.1 \\
\cline { 2 - 4 } & $25-40$ & 75 & 28.8 \\
\hline \multirow{3}{*}{ Pre malignancy } & Yes & 8 & 03.1 \\
\cline { 2 - 4 } & No & 252 & 96.9 \\
\hline \multirow{3}{*}{ CIN Grade } & CIN I & 8 & 100.0 \\
\cline { 2 - 4 } & CIN II & 0 & 0 \\
\cline { 2 - 4 } & CIN III & 0 & 0 \\
\hline
\end{tabular}

Table 2: Comparison of Cervical Pre-Malignancy on Pap Smear with Different Factors.

\begin{tabular}{|l|l|c|c|}
\hline \multicolumn{2}{|c|}{} & \multicolumn{2}{c|}{$\begin{array}{c}\text { Cervical Pre- } \\
\text { Malignancy On Pap } \\
\text { Smear }\end{array}$} \\
\cline { 3 - 4 } \multicolumn{2}{|c|}{} & Yes & No \\
\hline $\begin{array}{l}\text { History of } \\
\text { regular smoking }\end{array}$ & Yes & 0 & 0 \\
\cline { 2 - 4 } $\begin{array}{l}\text { History of Oral } \\
\text { contraception }\end{array}$ & No & 8 & 252 \\
\cline { 2 - 4 } $\begin{array}{l}\text { Low socio } \\
\text { economic status }\end{array}$ & No & 8 & 50 \\
\hline \multirow{2}{*}{\begin{tabular}{l} 
Parity \\
\cline { 2 - 4 }
\end{tabular}} & Yes & 8 & 202 \\
\hline \multirow{2}{*}{ Pregnancy } & Parity $<2$ & 1 & 130 \\
\cline { 2 - 4 } & Parity $>2$ & 7 & 60 \\
\hline \multirow{3}{*}{ Age at marriage } & Single & 6 & 239 \\
\cline { 2 - 4 } & Multiple & 2 & 13 \\
\cline { 2 - 4 } & $20-24$ & 4 & 160 \\
\cline { 2 - 4 } & $25-30$ & 0 & 75 \\
\hline
\end{tabular}

ried at the age < 19 years, 164 patients $(63.1 \%)$ at $20-$ 24 years of age and 75 patients $(28.8 \%)$ were married at the age of $25-40$ years. Cervical pre-malignancy on pap smear was observed in 8 patients $(3.1 \%)$ and all of them were CIN - I (Table 1.

\section{Discussion}

Second most common malignancy in females is cervical carcinoma and is third common cause of female mortality. 500,000 new cases of cervical carcinoma are diagnosed each year and responsible for 274,000 deaths. In Europe the crude mortality rate due to cervical carcinoma is 5.9/100,000 women/year and in developing countries mortality rate due to cervical carcinoma is 10 times higher. ${ }^{8}$ Cervical intraepithelial neoplasia (CIN) is growth of abnormal cells on cervix and it is premalignant condition of the cervix. ${ }^{9}$ Screening tests for cervical cancer include Pap smear and of human papillomavirus (HPV) DNA test. If screening test shows abnormalities then next step is colposcopy and cervical biopsy which may result in a diagnosis of CIN, glandular neoplasia, or cervical cancer. ${ }^{10}$

CIN is divided in to two type of lesions, low grade and high grade. Women having high grade lesion has more chances of developing cervical carcinoma as compare to women having low grade CIN. The reason of treating CIN is to prevent possible progression to cervical cancer and avoiding overtreatment of lesions that are likely to regress. These days rising incidence of CIN is noted among young women. For this reason pregnancy is high time and provides peculiar opportunity to undergo cytocolposcopic examination for those women who do not take part in a screening program for cervical carcinoma. When CIN is diagnosed during pregnancy, the question arises that whether it is better to treat the lesion or not during pregnancy. To contribute to the solution of this issue we initiated a study on the management of high-grade CIN in pregnancy. ${ }^{11}$

In present study majority of patients belonged to low socioeconomic status. 8 cases of cervical premalignancy on pap smear were having low socioeconomic class. Low socioeconomic factor for developing CIN is because of poor utilization of preventive services and subsequent presentation at late stage of disease. This study is comparable to the study carried out by Engelstad et al, in which revealed that low income women all at higher risk of developing cervical cancer. $^{12}$

Smoking is a potential risk factor for CIN because 
it reduces Langer cells in cells of cervical epithelial tissue. Due to religious, cultural and social factors it was not surprising to note that out of 260 , no one gave history of smoking. On other hand, Jubelirer et al, in 1996 reported that in screened females $40 \%$ cervical cancer has association with smoking risk. ${ }^{13}$ Early age of marriage is also risk factor of CIN. In the current study, it was observed that out of 8 cases of CIN, 4 women were having age $<19$ years and 4 women were having age between $20-24$ years at the onset of sexual activity. A study conducted in United States of America demonstrated that age at first sexual intercourse under -18 years is a high risk for developing CIN. ${ }^{14}$

For successful use of pap smear, however it is essential that patients can be screened on regular basis so that those women whose lesion have not detectable on the first smear will have such lesions detected on the next regular schedule screening examination. So that incidence as well as mortality and morbidity associated with cervical cancer could be further reduced in near future.

\section{Conclusion}

In conclusion, women having history of low socioeconomic status and oral contraceptive were more prevalent in developing CIN. It is recommended that cervical cancer screening by pap smear for all women who have been sexually active and who have cervix. For successful use of pap smear, however it is essential that patients can be screened on regular basis so that those women whose lesion have not detectable on the first smear will have such lesions detected on the next regular schedule screening examination. So that incidence as well as mortality and morbidity associated with cervical cancer could be further reduced in near future.

\section{References}

1. Shawz RW, Luesley D. Gynecology. Edinburgh: Churchill Livingstone, 2010: p.566-76.
2. Binesh F, Akhavan A, Pirdehghan A, Davoodi M. Does oral contraceptive pill increase the risk of abnormal Pap smear? Iran J Reprod Med. 2013; 11 (9): 761-6.

3. Kjær SK, Frederiksen K, Munk C, Iftner T. Long-term absolute risk of cervical intraepithelial neoplasia grade 3 or worse following human papillomavirus infection: role of persistence. J Nat Cancer Inst. 2010; 102 (19): 1478-88.

4. Kaminski P, Lyon DS, Sorosky JI, Wheelock JB, Podczaski ES. Significance of atypical cervical cytology in pregnancy. Am J Perinatol. 1991; 9 (5-6): 340-3.

5. Wasti S, Ahmed W, Jafri A, Khan B, Sohail R, Hassan $\mathrm{S}$. Analysis of cervical smears in a Muslim population. Ann Saudi Med. 2004; 24: 189-92.

6. Bal MS, Goyal R, Suri AK, Mohi MK. Detection of abnormal cervical cytology in Papanicolaou smears. J Cytol. 2012; 29 (1): 45-7.

7. Edmonds ED. Dewhurst's textbook of obstetrics and gynecology. Wiley - Blackwell, 2012: P. 747-52.

8. Cervical cancer: ESMO Clinical Practice Guidelines for diagnosis, treatment and follow-up, European Society for Medical Oncology, 2010.

9. Montz F. Management of high - grade cervical intraepithelial neoplasia and low - grade squamous intraepithelial lesion and potential complications. Clinic Obs and Gynecol. 2000; 43 (2): 394-409.

10. Massad LS, Einstein MH, Huh WK, Katki HA, Kinney WK, Schiffman M. 2012 updated consensus gui-delines for the management of abnormal cervical cancer screening tests and cancer precursors. Obs \& Gynecol. 2013; 121 (4): 829-46.

11. Penna C, Fallani M, Maggiorelli M, Zipoli E, Cardelli A, Marchionni M. High - grade cervical intraepithelial neoplasia (CIN) in pregnancy: clinicotherapeutic management. Tumori. 1997; 84 (5): 567-70.

12. Engelstad LP, Stewart SL, Nguyen BH, Bedeian KL, Rubin MM, Pasick RJ. Abnormal Pap smear follow-up in a high - risk population. Cancer Epi-demiology Biomarkers and Prevention, 2001; 10 (10): 1015-20.

13. Jubelirer SJ, Blanton MF, Blanton PD, Zhang J, Foster $\mathrm{D}$, Monk J, et al. Assessment of knowledge, attitudes, and behaviors relative to cervical cancer and the Pap smear among adolescent girls in West Virginia. J Cancer Edu. 1996; 11 (4): 230-2.

14. Cyrus-David MS, Michielutte R, Paskett ED, D'Agostino R, Goff D. Cervical cancer risk as a predictor of Pap smear use in rural North Carolina. J Rural Health, 2002; 18 (1): 67-76. 